\title{
OCCIPITAL CONDYLE FRACTURE IN A PATIENT WITH HEAD TRAUMA
}

\author{
Wellingson Silva Paiva, Eloy Rusafa-Neto, Robson Luis Oliveira Amorim, \\ Eberval Gadelha Figueiredo, Almir Ferreira de Andrade, Manoel Jacobsen Teixeira
}

An occipital condyle fracture (OCF) was described by Sir Charles Bell in 1817'. Occipital condyle fracture is a rare injury and the radiology and trauma literature is limited to a few cases $^{2-4}$. An important aspect of OCF relates to the difficulty in elucidating the diagnosis of condylar injury. The variation in symptoms and the inability to delineate the fracture by plain cervical spine or cranial radiography produce a diagnostic challenge. In contrast, computed tomographic scan(CT) evaluation is conclusive in all cases $^{5}$. Occipital condyle fracture rarely comes to clinical observation, often being associated with fatal trauma ${ }^{6}$. In many autopsies of victims of head trauma, OCFs ranged from 0.6 to $4.2 \%$. We describe a case of a patient with condyle fracture associated with brain contusion.

\section{CASE}

A 36-year-old female was admitted to the emergency room following a motor vehicle accident. The exact speed and circumstances of the incident were unclear. On admission her Glasgow Coma Score (GCS) was 14, and she had reactive and isochoric pupils, without systemic lesion. No signs of lower cranial nerve paralysis were observed. Immediate head (Fig 1A) and cervical column multislice CT scan were performed and a frontotempo- ral contusional hematoma with mild cerebral edema was seen. A detailed CT scan of cranio-cervical junction revealed a fracture of the left occipital condyle (Fig 2). In head CT control after 6 hours (Fig 1B), the brain contusion increased and her GCS dropped to 13 points. We performed a frontotemporal craniotomy and the brain hematoma was drained (Fig 1C). We maintained neutral position of the head during the surgical procedure. No surgical treatment for condyle fracture was adopted. Cervical immobilization with Philadelphia necklace was kept even to the fifth day post-surgery. The patient was discharged from hospital on the sixth day postoperative with fourteen points in GCS for aphasia component, with no deficits or cervical pain. After two months, the patient recovered from aphasia and improved the GCS to 15 , with no cervical pain or motor deficits.

\section{DISCUSSION}

Occipital condyle fractures typically occur in association with multiple injuries sustained from high-energy blunt trauma. Hanson et al. ${ }^{9}$ estimated the incidence as occurring in approximately $0.10 \%$ of patients. In 1988, Anderson and Montesano described three types of OCFs based on their radiographic appearance and presumptive mechanism of injury ${ }^{10}$. The type I OCF, produced by an axial load
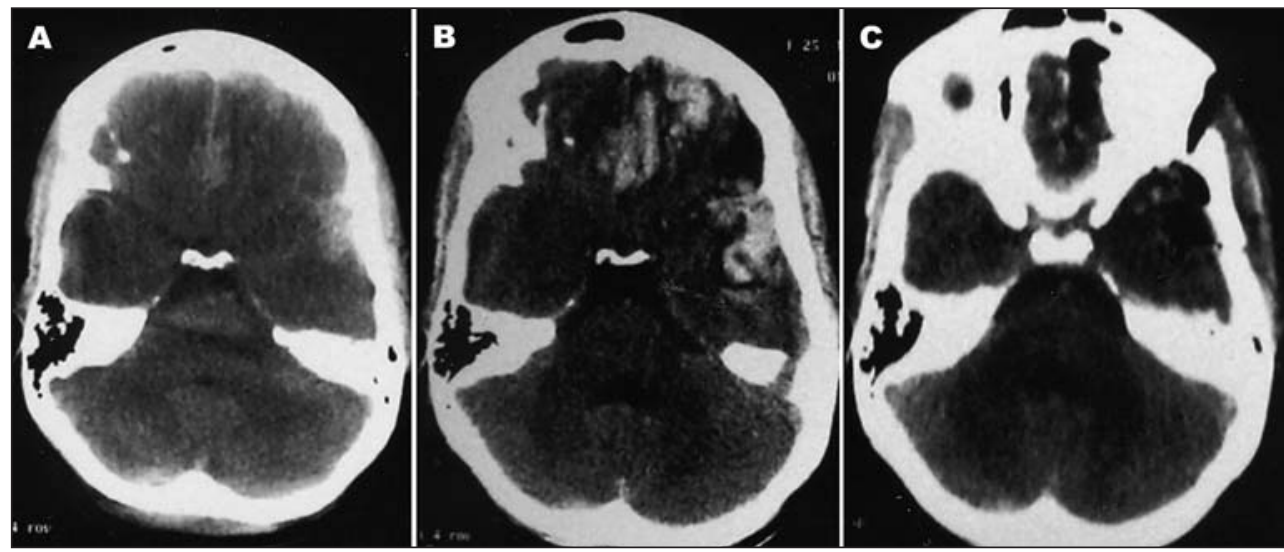

Fig 1. Head CT patient 25 years old, in (A) admission CT, in (B) CT after 6 hours, in (C) postoperative CT.

FRATURA DE CÔNDILO OCCIPITAL EM PACIENTE COM TRAUMA CRANIOENCEFÁLICO

Division of Neurosurgery, Hospital das Clínicas, University of São Paulo Medical School, São Paulo SP, Brazil.

Received 12 May 2008, received in final form 16 October 2008. Accepted 24 November 2008.

Dr. Wellingson Silva Paiva - Rua Teodoro Sampaio 498 / Ap 66 - 05406-000 São Paulo SP - Brasil. E-mail: wellingsonpaiva@yahoo.com.br 

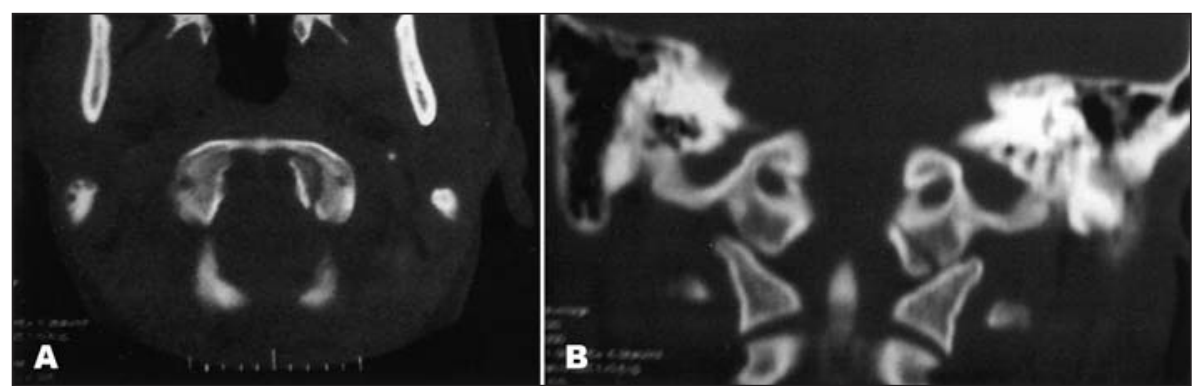

Fig 2. Multislice CT cranio-cervical junction revealed fracture of the left occipital condyle.

injury with a component of ipsilateral flexion, is considered an impaction fracture of the occipital condyle. The type II OCF refers to a basilar skull fracture that extends to involve the occipital condyle and is usually the result of a direct blow to the skull. The fracture line can reach the condyle after crossing either the more posterior squamous portion of the occipital bone or the more anterior basiocciput. The type III OCF is essentially an avulsion fracture of the inferomedial portion of the condyle, it is most probably the result of severe contralateral flexion and rotation.

The conservative management of patients with OCF is the standard treatment. Immobilization in a hard collar is the treatment of choice for stable and undisplaced fractures. Immobilization for approximately three months is recommend, with a range of $1-3$ months ${ }^{11,12}$. Decompressive surgery is indicated if severe brainstem or transition spine cord-brainstem compression occurs. Surgical decompression for this type of fracture has been reported only five times ${ }^{13-15}$. Unstable fractures may be treated with immobilization in halo vest or occipito-cervical fixation ${ }^{16}$.

More recently, Tuli et al. ${ }^{16}$ reviewed the published cases of occipital condyle fracture and proposed the following new classification system: type 1, nondisplaced occipital condyle fracture (stable); type 2A, displaced occipital condyle fracture with intact ligaments (stable); and type 2B, displaced occipital condyle fracture with radiographic evidence of craniocervical junction instability. Tuli et al. ${ }^{16}$ postulated that their classification can guide neurosurgical management: type $2 \mathrm{~B}$ fractures require surgical instrumentation or halo traction, whereas type $2 \mathrm{~A}$ injuries may be treated with a rigid collar, and type 1 injuries require no specific treatment ${ }^{12}$.

From our review of clinical reports, $68 \%$ of OCFs were associated with good clinical status ${ }^{4,5,10}$. In our case OCF was isolated, without associated cranial nerve lesions. Then, OCF per se is not a fatal injury, except the cases with brainstem compression by fractured condyle. In our patient the fracture could be classified as type I, that is considered a stable injury, because the tectorial membrane and contralateral alar ligament were not disrupted.
In our patient, no specific treatment was adopted and in the surgery for frontotemporal brain contusion, neck and head were maintained in neutral position.

Fractures of the occipital condyles are more commonly identified on CT screening. The real incidence of these fractures is unknown. However, routine use of mutislice $\mathrm{CT}$ resulted in an increase of diagnosis of these fractures in the past decade. Upon patient admission, the early diagnosis of OCF is important to perform the classification by Anderson ${ }^{10}$ or Tulli ${ }^{16}$ methods for correct and early treatment. The correct management is also critical in patients submitted to craniotomy, whose the correct neck and head position are essential to avoid additional injury.

\section{REFERENCES}

1. Bell C. Surgical observations. Middlesex Hospital Journal 1817;4: 469-470.

2. Young WF, Rosenwasser RH, Getch C, Jallo J. Diagnosis and management of occipital condyle fractures. Neurosurgery 1994;34:257-261

3. Bloom AI, Neeman Z, Slasky BS, et al. Fracture of the occipital condyles and associated craniocervical ligament injury: incidence, CT imaging and implications. Clin Radiol 1997;52:198-202.

4. Leone A, Cerase A, Colosimo C, Lauro L, Puca A, Marano P. Occipital condylar fractures: a review. Radiology 2000;216:635-644.

5. Caroli E, Rocchi G, Orlando ER, Delfini R. Occipital condyle fractures: report of five cases and literature review. Eur Spine J 2005;14: 487-492.

6. Ahlgren P, Dahlerup JV. Fracture of the occipital condyle: a new case of isolated fracture. Fortschr Geb Rontgenstr Nuklearmed 1964;101:202-204.

7. Alker GJ, Oh YS, Leslie EV. High cervical spine and cranio-cervical junction injuries in fatal traffic accidents: a radiological study. Orthop Clin N Am 1978;9:1003-1010

8. Bucholz RW, Burkhead WZ. The pathological anatomy of fatal atlantooccipital dislocations. J Bone Joint Surg Am 1979;61:248-250.

9. Hanson JA, Deliganis AV, Baxter AB, et al. Radiological and clinical spectrum of occipital condyle fracture: retrospective review of 107 consecutive fractures in 95 patients. Am J Roentgenol 2002;178:1261-1268.

10. Anderson PA, Montesano PX. Morphology and treatment of occipital condyle fractures. Spine 1988;13:731-736.

11. Massaro F, Lanotte M.Fracture of the occipital condyle. Injury 1993;24: 419-420.

12. Ide C, Nisolle JF, Misson N, et al. Unusual occipitoatlantal fracture dissociation with no neurological impairment: case report. J Neurosurg 1998;88:773-776.

13. Fuentes S, Bouillot P, Dufour H, Grisoli F. Occipital condyle fractures and clivus epidural hematoma: case report. Neurochirurgie 2000;46: 563-567.

14. Gusmao SS, Silveira RL, Arantes A. Surgical treatment of the occipital condyle fracture: case report. Arq Neuropsiquiatr 2001;59:134-137.

15. Bozboga M, Unal F, Hepgul K, Izgi N,Turatan I, Turker K. Fracture of the occipital condyl: case report Spine 1992;17:1119-1121.

16. Tuli S, Tator $\mathrm{CH}$, Fehlings MG, Mackay M. Occipital condyle fractures. Neurosurgery1997;41:368-377. 